\title{
EKSPLORASI TEKNIS FOTOGRAFI UDARA POROS IMAJINER DAERAH ISTIMEWA YOGYAKARTA
}

\author{
Oscar Samaratungga \\ Dosen Jurusan Fotografi, Fakultas Seni Media Rekam, ISI Yogyakarta \\ Jalan Parangtritis Km 6,5 Bantul, Yogyakarta \\ No.Hp.: +6282225035294, E-mail: oscar.keken@gmail.com
}

\begin{abstract}
ABSTRAK
Yogyakarta adalah kota yang unik dan istimewa, salah satunya karena adanya filosofi tentang garis imajiner. Garis imajiner itu sudah menjadi wacana lama, tetapi tetap menarik untuk menjadi pembahasan. Kota ini terbelah sebuah oleh sumbu imajiner yang menghubungkan Gunung Merapi - Tugu Pal Putih - Keraton - Panggung Krapyak - Parangtritis. Dilihat dari peta, juga bisa dilihat jika Merapi, Keraton, dan Pantai Selatan ini memang berada di satu garis lurus secara imajiner. Filosofi garis lurus imajiner dari Merapi hingga Laut Selatan ini sarat makna. Untuk masyarakat di Yogyakarta, Gunung Merapi, Laut Selatan, dan Keraton Yogyakarta mengandung makna penting. Kehidupan di dunia merupakan sebuah harmoni antara mikrokosmos (jagat cilik) dan makrokosmos (jagat gede). Keharmonisan itu harus dijaga satu sama lain, tidak boleh terjadi ketimpangan. Tujuan dari penelitian ini adalah bagaimana melakukan eksplorasi pemotretan udara atas poros imajiner dikaitkan dengan teknis kreatif dan aspek estetis yang dapat mengungkap kekhasan wilayah Daerah Istimewa Yogyakarta. Pemotretan yang akan dilakukan adalah pemotretan melalui udara menggunakan drone, sebuah peralatan dan teknologi baru yang sedang berkembang dalam dunia fotografi saat ini. Lokasi yang akan direkam dan didokumentasikan adalah lima titik yang ada dalam poros imajiner tersebut, yaitu Gunung Merapi, Tugu Pal Putih, Keraton, Panggung Krapyak, dan Parangtritis. Salah satu kekuatan dalam fotografi udara dengan menggunakan drone adalah keleluasaan dalam menempatkan kamera. Keleluasaan penempatan kamera tersebut membuka ruang eksplorasi dalam mengambil gambar dari berbagai sudut yang berbeda. Gambar dari sudut yang berbeda tersebut dapat memberikan cara pandang yang berbeda pula. Hal ini berarti ruang hampir tidak terbatas untuk mengekplorasi berbagai sudut yang mungkin sulit dijangkau ketika menggunakan medium fotografi lainnya.
\end{abstract}

Kata kunci: eksplorasi, fotografi udara, poros imajiner, drone

\section{ABSTRACT}

Aerial Photography Technical Exploration of the Special Region of Yogyakarta's Imaginary Axis. Yogyakarta is a unique and special city, one of them is because of the philosophy of the Imaginary Line. Although the imaginary line has become an old discourse, it is still interesting to be discussed. The city is split by an imaginary axis connecting Mount Merapi - Tugu Pal Putih - Keraton - Panggung Krapyak -Parangtritis. Explored from the map, it can also be seen that Merapi, Keraton and South Coast are indeed in one imaginary straight line. The philosophy of imaginary straight lines from Merapi to the South Sea is full of meaning. For people in Yogyakarta, Mount Merapi, the South Sea, and Yogyakarta Palace, they have their own important meaninga. Life in the world is a harmony between the microcosm (the universe) and the macrocosm (big universe). The harmony must be maintained with each other, inequality must not occur. The purpose of this study is to explore aerial photography of an imaginary axis associated with creative technical and aesthetic aspects that can reveal the peculiarities of the Special Region of Yogyakarta. The photos taken are aerial photography using Drones, a new equipment and technology that is developing in the world of photography today. The locations that were recorded and documented were the five points in the imaginary 
axis, namely Mount Merapi, Tugu Pal Putih, Keraton, Panggung Krapyak, and Parangtritis. One of the strengths in aerial photography using drones is the flexibility in placing the camera. The flexibility of placing the camera opens an exploration of space in taking pictures from different angles, because images from different angles can provide a different perspective. This means there is an unlimited space to explore various angles that may be difficult to reach when using other photography mediums.

Keywords: aerial photography, exploration, imaginary line, drone

\section{PENDAHULUAN}

Daerah Istimewa Yogyakarta merupakan daerah yang mempunyai adat istiadat dan kebudayaanyangmasih dilestarikan. Halinitidak bisa lepas dari adanya Keraton Nagyogyakarta Hadiningrat dan Puro Pakualaman yang masih mempertahankan tradisi secara turuntemurun. Kedua tempat tersebut juga menjadi salah satu tujuan wisata bagi para wisatawan yang berkunjung ke Yogyakarta. Yogyakarta memang istimewa, berbagai keunikan yang mengagumkan dapat ditemukan di kota gudeg ini. Mulai dari objek wisata, budaya, hingga sejarah yang menarik untuk diikuti. Yogyakarta juga memiliki segudang sejarah, tercatat dalam sejarah kemerdekaan Republik Indonesia, sejarah tokoh-tokoh intelektual dan spiritual dalam masa kemerdekaan, hingga sejarah kerajaan dan kebudayaan. Oleh karena itu, selain mendapat sebutan kota budaya juga sering disebut kota pelajar. Selain itu juga terdapat filosofi dari berbagai kebudayaan dan sejarah tersebut.

Salah satu yang menjadikan Yogyakarta lebih unik dan istimewa adalah adanya filosofi tentang garis imajiner. Garis imajiner itu sudah menjadi wacana lama, tetapi tetap menarik untuk menjadi pembahasan. Kota ini terbelah oleh sebuah sumbu imajiner yang menghubungkan Gunung Merapi-Tugu Pal Putih - Keraton Panggung Krapyak - Parangtritis. Memang unik, ternyata dilihat dari map/peta juga bisa dilihat jika Merapi, Keraton dan Pantai Selatan ini memang berada di satu garis lurus secara imajiner. Pada umumnya warga Yogyakarta sudah memahami maknanya, struktur kota memiliki filosofis simbolis yang berdasar pada garis imajiner Gunung Merapi-Tugu-KeratonPanggung Krapyak-Laut Selatan (Parang Kusumo). Filosofi garis lurus imajiner dari Merapi hingga Laut Selatan ini sarat makna. Untuk masyarakat di Yogyakarta, Gunung Merapi, Laut Selatan dan Keraton Yogyakarta mengandung makna penting. Kehidupan di dunia merupakan sebuah harmoni antara mikrokosmos (jagat cilik) dan makrokosmos (jagat gede). Keharmonisan itu harus dijaga satu sama lain, tidak boleh terjadi ketimpangan. Peran Gunung Merapi dan Laut Selatan ini dipercaya sebagai pusat kedudukan mikrokosmos (jagat cilik), sedangkan Keraton merupakan pusat makrokosmos (jagat gede). Akan tetapi, dalam kajian ini tidak akan terlalu dalam membahas filosofi garis imajiner tersebut, tetapi lebih pada bidang fotografi, yaitu eksplorasi teknik fotografi udara yang akan merekam dan mendokumentasikan lima titik yang ada dalam poros imajiner tersebut, yaitu Gunung Merapi, Tugu Pal Putih, Keraton, Panggung Krapyak, dan Parangtritis. Pemotretan yang akan dilakukan adalah melalui udara menggunakan drone, yaitu sebuah peralatan dan teknologi baru yang sedang berkembang dalam dunia fotografi saat ini. 
Tentu sudah banyak foto dokumentasi tentang tempat-tempat yang ada dalam poros imajiner tersebut, dari era foto analog hingga era digital seperti saat ini. Hal ini karena sudah banyak orang yang mengunjungi tempat-tempat tersebut yang memang menjadi tujuan wisata bila berkunjung ke Yogyakarta. Seiring dengan perkembangan kamera digital, dengan mudah dapat dijumpai foto tempat-tempat tersebut di dalam majalah, koran, dan internet. Walaupun foto-foto tersebut dipotret secara terpisah dan mungkin juga dalam rentang waktu yang berbeda, bahkan kemungkinan juga sebagian besar foto yang ada tidak bermaksud secara langsung untuk menggambarkan poros imajiner di Yogyakarta. Ada sebuah pemahaman yang menyatakan bahwa memotret objek yang sama, yang dilakukan oleh orang yang sama hasilnya pasti akan berbeda walaupun menggunakan alat yang sama. Hal ini terkait dengan pengalaman dan latar belakang estetis dari orang tersebut. Apalagi jika dilakukan pemotretan dari udara tentu imaji visual yang ditawarkan akan menjadi lebih menarik karena perspektif yang jarang sekali orang lihat dan lakukan. Seperti halnya jika saat naik pesawat terbang, saat melihat pemandangan pegunungan, laut, dan kota dari udara akan terasa sangat menarik. Penciptaan fotografi pemotretan udara poros imajiner Daerah Istimewa Yogyakarta ini dikaitkan dengan aspek estetis dan teknis kreatif.

Berdasarkan latar belakang yang telah dikemukakan, dapat dirumuskan bahwa permasalahan yang akan dibahas adalah bagaimana melakukan eksplorasi pemotretan udara atas poros imajiner dikaitkan dengan teknis kreatif dan aspek estetis yang dapat mengungkap kekhasan wilayah Daerah Istimewa Yogyakarta.

\section{TINJAUAN PUSTAKA}

Tugas Akhir Setiawan (1999), Jurusan Fotografi, FSMR, ISI Yogyakarta, yang berjudul "Yogyakarta dari Udara". Pada tugas akhirnya ia menampilkan wajah Yogyakarta dari udara dengan menggunakan pesawat/ helikopter. Ia bercerita bahwa ada sensasi yang luar biasa ketika mengambil foto dari udara, baik secara fisik maupun mental. Secara fisik misalnya bagaimana tangan menjadi kaku karena berada di atas ketinggian, secara mental adalah adrenalin yang terpompa karena manusia berada di kondisi yang tidak biasa (berada di udara). Dalam karyanya ia lebih berfokus pada penampilan bentuk dan warna ketika berada di udara. Apa yang dilakukan sangat luar biasa karena tingkat kesulitan yang cukup tinggi, yaitu karena menggunakan helikopter harus berada di ketinggian atau jarak tertentu dari sebuah objek foto, susah melakukan manuver tertentu demi mendapat sudut atau angle yang menarik (Gambar 1). Apalagi pada saat itu ia masih menggunakan kamera film.

Tugas Akhir Karya Seni Yusuf (2015), Program Studi Pendidikan Seni Rupa, Fakultas Bahasa dan Seni, Universitas Negeri Yogyakarta, yang berjudul "Landmark Yogyakarta Sebagai Objek Penciptaan Karya Fotografi". Dalam penciptaan fotografi ini ia sudah menggunakan alat bantu berupa drone untuk melakukan pemotretan dari udara. Tempat yang dipilih sebagai landmark Yogyakarta adalah Monjali, Tugu, Stasiun Tugu, Monumen 1 Maret, Kantor POS \& Kantor BNI, Keraton, Mesjid Gedhe, Pulo Kenanga, Tamansari, dan Puro Pakualaman. Selanjutnya ia melakukan rekayasa digital untuk mencapai sebuah imaji visual yang lazim disebut smallgantics, yaitu memberi kesan miniatur terhadap objek yang difoto (Gambar 2). 


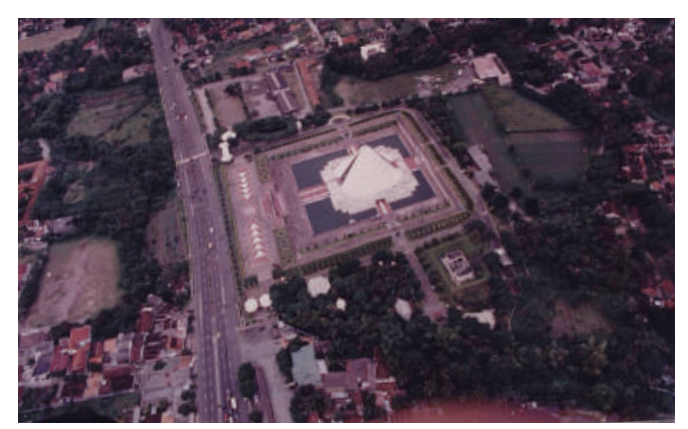

Gambar 1

Gunungan Bumi

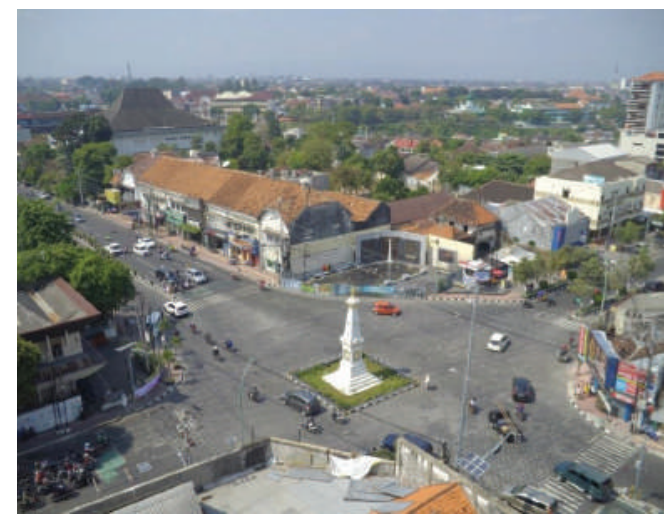

Gambar 2

Antara Orientasi dan Representasi Kota

Artikel Suroso (2018) tentang "Analisis

Peran Unmanned Aerial Vehicle Jenis Multicopter dalam Meningkatkan Kualitas Dunia Fotografi Udara di Lokasi Jalur Selatan Menuju Calon Bandara Baru di Kulonprogo". Drone berdasarkan jenisnya terdapat dua jenis, yaitu multicopter dan fixed wing. Fixed wing memiliki bentuk seperti pesawat terbang biasa yang dilengkapi sistem sayap. Drone dalam penelitian ini memiliki empat propeller yang digunakan untuk pemetaan jalur selatan menuju bandara baru Yogyakarta International Airport yang terletak di Desa Plumbon, Kecamatan Temon, Kabupaten Kulonprogo. Drone ini memiliki kemampuan beban $1 \mathrm{~kg}$ dan waktu operasional digunakan kurang lebih 20 menit untuk area 50 sampai dengan 100 hektar dengan ketinggian mencapai $1.500 \mathrm{~m}$ di atas permukaan tanah.

\section{LANDASAN TEORI}

\section{Fotografi Udara}

Setelah daratan, manusia mencoba untuk membawa fotografi ke sudut pandang lain, yaitu udara. Sejatinya, mimpi untuk bisa terbang sudah ada di benak manusia sejak lama, karena manusia mempunyai keinginan untuk "melihat dari atas". Melihat dari sudut pandang yang berbeda, menemukan pengalaman visual baru dari sudut pandang seekor burung yang sedang terbang atau dikenal orang dengan sebutan "bird eye view".

Usaha pertama untuk membuat fotografi udara dilakukan oleh Gaspard-Felix Tomachon atau biasa dikenal dengan Nadar. Seorang balloonist dan fotografer berkebangsaan Perancis. Pada tahun 1858 ia muncul dengan ide 'gila' untuk memetakan kota atau daerah tempat tinggalnya. Namun usahanya gagal karena kendala teknis, tidak ada satu pun foto pada ekspedisi pertamanya yang terwujud. Namun, ide 'gila' tersebutlah yang menjadi cikal bakal foto udara sebagai media mendobrak keterbatasan manusia yang tidak ditakdirkan untuk bisa terbang (Hawkess \& McConnel, 2003).

Perspektif baru yang menarik, yaitu melihat ke bawah dari arah atas adalah perspektif yang jarang orang lakukan. Karena pada umumnya untuk mencapai hal tersebut harus mencari tempat yang lebih tinggi, misalnya gedung tingkat, menara, memanjat pohon atau mencari dataran tinggi, serta mendaki bukit dan gunung. Pengalamanpengalaman menarik ketika melihat dari atas tersebutlah yang menginspirasi manusia untuk mencoba mengabadikan pemandangan indah atau kejadian menarik tersebut dengan kamera. Fotografi udara adalah pengambilan gambar dari sudut yang tinggi, biasanya tidak dipasang pada suatu struktur di darat (Papilaya, 2015). 


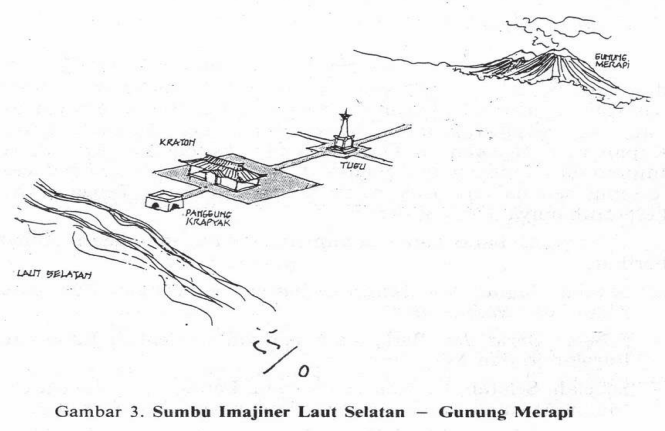

Gambar 3. Poros Imajiner

Sumber: https://www.students.id/menguak-garisimajiner-jogja-merapi-tugu-kraton-dan-pantaiselatan/

\section{Poros Imajiner Daerah Istimewa Yogyakarta}

Daerah Istimewa Yogyakarta (DIY) adalah sebuah daerah otonomi setingkat provinsi di Indonesia dengan ibu kota Yogyakarta. Daerah Istimewa yang memiliki luas $3.185,80 \mathrm{~km}^{2}$ ini terdiri atas satu kota madya, dan empat kabupaten, yang terbagi lagi menjadi 78 kecamatan, dan 438 desa/kelurahan.

Menurut sensus penduduk 2010 memiliki populasi 3.452 .390 jiwa dengan proporsi 1.705.404 laki-laki, dan 1.746 .986 perempuan, serta memiliki kepadatan penduduk sebesar 1.084 jiwa per $\mathrm{km}^{2}$.

Sejak dahulu, Kota Yogyakarta sudah terkenal sebagai salah satu kota yang unik dalam hal bentuk pola tata ruangnya. Keunikan ini karena dalam tata ruang kota terdapat suatu poros sumbu imajiner. Poros ini membentang dari arah Utara - Selatan (Gunung Merapi Tugu Pal Putih - Kraton Yogyakarta - Panggung Krapyak - Laut Selatan) membentuk suatu jalur linear dan menghubungkan beberapa simbol fisik yang mempunyai makna nilai filosofis.

Gunung Merapi terletak di perbatasan DIY dan Jawa Tengah, yang juga sebagai batas utara Yogyakarta. Di sinilah garis 1 Wikipedia: Ensiklopedia Bebas, diakses pada Sabtu, 25 Maret 2017, pukul 18.00 WIB. lurus itu dimulai. Membujur ke arah selatan, terdapat Tugu Yogya. Tugu menjadi simbol 'manunggaling kawulo gusti' yang juga berarti bersatunya antara raja (golong) dan rakyat (gilig). Simbol ini juga dapat dilihat dari segi mistis, yaitu persatuan antara khalik (Sang Pencipta) dan makhluk (ciptaan).

Garis selanjutnya mengarah ke Keraton dan kemudian lurus ke selatan terdapat Panggung Krapyak. Gedhong Panggung, demikian bangunan itu kini disebut, merupakan podium batu bata setinggi 4 meter, lebar 5 meter, dan panjang 6 meter. Tebal dindingnya mencapai 1 meter. Bangunan di sebelah selatan Keraton ini menjadi batas selatan kota tua Yogyakarta. Titik terakhir dari garis imajiner itu adalah Pantai Parang Kusumo.

\section{Teknis Kreatif dan Aspek Estetis}

Fotografi merupakan perpaduan antara teknologi dan seni. Perkembangan teknologi dalam dunia fotografi digital sudah sangat pesat. Fotografi merupakan salah satu dari sekian banyak bentuk media visual yang telah berkembang seiring dengan kemajuan zaman. Hal ini diwujudkan dengan semakin beragamnya alat juga aksesoris yang diciptakan dan digunakan oleh manusia untuk merekam, mendokumentasikan, atau bahkan berekspresi dengan medium fotografi. Imaji visual fotografi merupakan media yang representatif kebenarannya yang dapat memindahkan imaji dan merekam suatu realitas dan apa adanya atas suatu objek dari suatu realitas peristiwa dengan sangat sempurna.

Seperti yang dikatakan oleh Tubagus P. Svarajati dalam bukunya Photagogos, Terang Gelap Fotografi Indonesia (Svarajati, 2013) bahwa: "Kode-kode realitas-ruang-waktu itu dimanfaatkan sedemikian rupa-hanya- 
dalam selembar kertas. Fenomena itu akan hadir dalam kesepenuhan maknawinya bagi siapa pun seturut historisitasnya dan dalam kontekstualitasnya sendiri, meskipun dimensi nilai-nilainya tidak seragam bagi setiap orang..

Dengan demikian, imaji visual fotografi digunakan sebagai salah satu media yang menyatakan kebenaran atau bukti, sebagai media untuk pengingat atau memori masa lalu dan sebagai penanda simbol historis yang kehadirannya merupakan otentisitas suatu kejadian atau peristiwa yang telah terjadi pada masa itu.

Perkembangan teknologi dalam dunia fotografi diterima dengan tangan terbuka, baik oleh pecinta fotografi profesional, amatir, dan bahkan oleh masyarakat awam sekali pun. Terbukti masyarakat yang dulunya hanya penikmat produk fotografi, sekarang justru bisa menjadi penikmat sekaligus pelaku bidang fotografi, yaitu dalam hal menghasilkan gambar atau foto. Masyarakat modern sudah tidak asing dengan aktivitas fotografi yang menjadi bagian dari kegiatan mereka, untuk mengabadikan suatu peristiwa, keadaan, atau objek benda tertentu. Kegiatan ini menjadi suatu hal yang lumrah dan diapresiasi banyak orang. Terbukti dengan makin banyaknya orang memiliki kamera. Memotret atau mengambil gambar untuk diabadikan merupakan bagian dari kegiatan manusia saat ini. Kemajuan bidang teknologi khususnya teknologi digital berkembang sangat pesat sehingga aktivitas fotografi menjadi milik semua orang. Hal ini dibuktikan dengan masyarakat awam yang begitu mudah melakukan kegiatan memotret apa pun dengan menggunakan kamera handphone atau kamera saku digital.

Perkembangan tentang gagasan dalam proses penciptaan karya seni fotografi pun telah menjelajah berbagai kemungkinan baru. Di satu sisi, hal ini tampak dengan sangat jelas pada perkembangan teknologi dalam seni fotografi, terutama dalam teknologi yang melekat dengan peralatan kamera foto. Di sisi lain, juga tampak dalam perkembangan penggayaan dalam seni fotografi, yang sekaligus juga perkembangan bagi bentuk dan identifikasi dari suatu ekspresi diri seorang seniman fotografi. Hal ini sangat sepadan dengan pernyataan bahwa secara ideational (gagasan), wacana fotografi berkembang dari kesadaran manusia sebagai makhluk yang berbudi/berakal yang memiliki kemampuan lebih untuk dapat merekayasa alam lingkungan kehidupannya. Hal ini merupakan alasan yang kuat untuk memungkinkannya tetap 'survive' dan menciptakan berbagai 'karya kehidupan' sebagai 'tanda' eksistensinya di dunia ini (Soedjono, 2007). Dengan demikian, dalam konteks seni fotografi terlihat bagaimana upaya manusia, sebagai seorang fotografer, menyikapi setiap fenomena alam dengan menemukan suatu dorongan proses kreatif yang akan mewujudkan suatu karya seninya.

\section{PEMBAHASAN}

Dunia fotografi udara adalah dunia tiga dimensi yang cukup rumit dan membingungkan karena semua terlihat menarik dilihat dari sudut yang sangat jarang bisa dilihat oleh mata manusia. Salah satu kekuatan dalam fotografi udara menggunakan drone adalah keleluasaan dalam menempatkan kamera (Cheng, 2016), sesuatu yang tidak bisa dicapai dengan menggunakan teknik fotografi lainnya, termasuk jika dibandingkan dengan media untuk membawa fotografi ke udara seperti helikopter atau pesawat terbang. Keleluasaan penempatan kamera tersebut membuka ruang eksplorasi dalam mengambil gambar dari berbagai sudut yang berbeda, 
gambar dari sudut yang berbeda tersebut dapat memberikan cara pandang yang berbeda pula.

Oren Schauble \& Roger Sollenberger menjelaskan ada dua macam sudut pengambilan gambar dalam fotografi udara, yaitu: (a) tegak lurus (straight down/vertical); pengambilan gambar tegak lurus (straight down) adalah sudut pengambilan yang menghasilkan imaji vertikal dan (b) menyamping/serong (angled/oblique); sudut pengambilan gambar menyamping/ serong menghasilkan imaji yang menampilkan perspektif (Scrauble \& Sollenberger, 2016).

Kemajuan teknologi memungkinan karya dengan tampilan baru tercipta, salah satunya adalah menggabungkan beberapa gambar menjadi satu. Beberapa tujuannya adalah mendapatkan gambar yang lebih besar dan luas contohnya adalah foto panorama, hal yang mendorong munculnya foto panorama karena keterbatasan sudut padang yang mampu dilihat oleh mata manusia (kurang lebih 40 derajat) sementara dunia pada sudut 360 derajat (Davis, 2010).

Hasil penelitian/penciptaan sementara telah dicapai adalah beberapa foto dari kelima titik di dalam poros imajiner tersebut, yaitu Gunung Merapi, Tugu Yogyakarta, Keraton, Kandang Menjangan, dan Pantai Parangtritis. Tentu tidak hanya sekali atau dua kali melakukan pemotretan ke masing-masing lokasi untuk bisa mendapatkan gambar yang baik dan momen yang bagus. Berikut beberapa foto dari Poros Imajiner Yogyakarta; Gunung Merapi, Tugu, Keraton, Kandang Menjangan, dan Pantai Parangtritis.

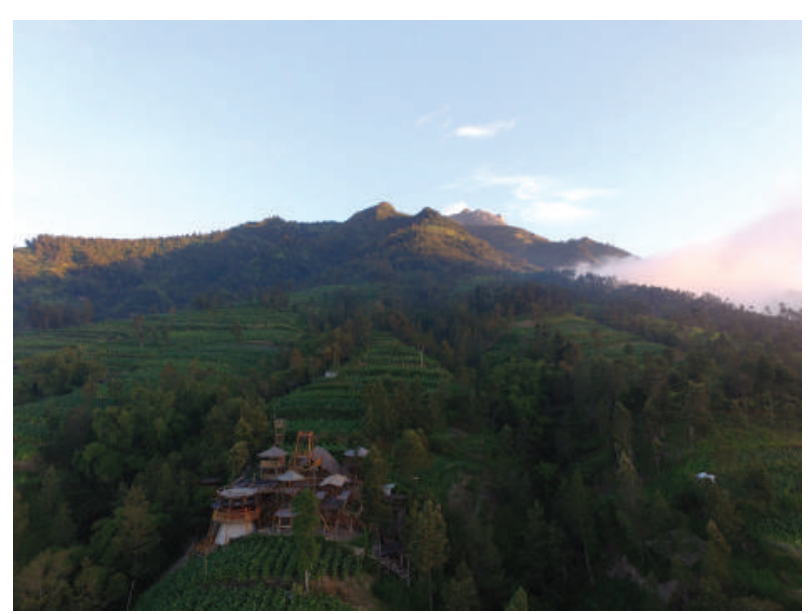

Gambar 4. Gunung Merapi

Difoto dengan sudut menyamping/serong (angled/ oblique). Menggambarkan Puncak Gunung Merapi dan salah satu lerengnya. Gunung Merapi merupakan titik paling utara dari rangkaian poros imajiner.

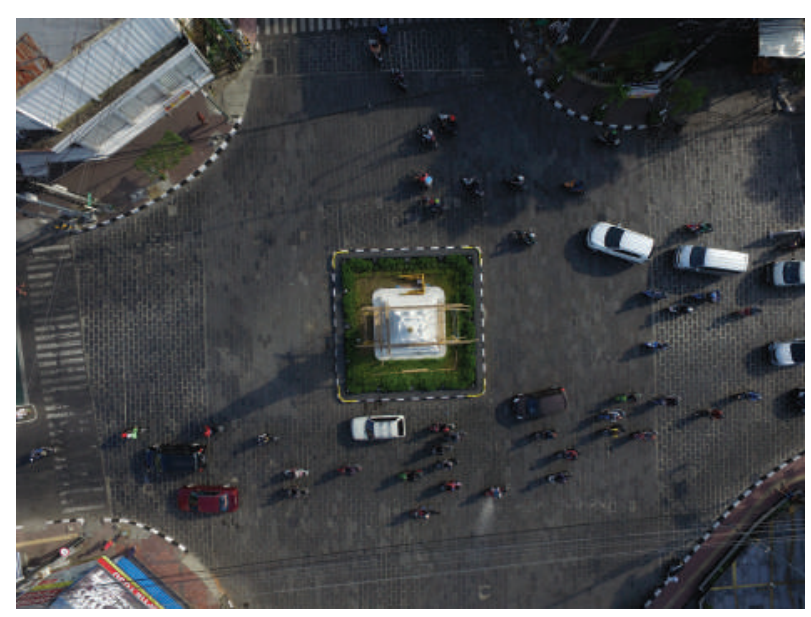

Gambar 5. Tugu Jogja

Difoto dengan sudut tegak lurus (straight down/ vertical). Menggunakan drone berarti memiliki kebebasan dalam penempatan kamera. Ruang yang hampir tidak terbatas untuk mengeksplorasi berbagai sudut yang mungkin sulit dijangkau ketika menggunakan medium fotografi lainnya. Dengan memotret tegak lurus dari atas Tugu Jogja tampil berbeda karena difoto dari sudut yang tidak biasa. 


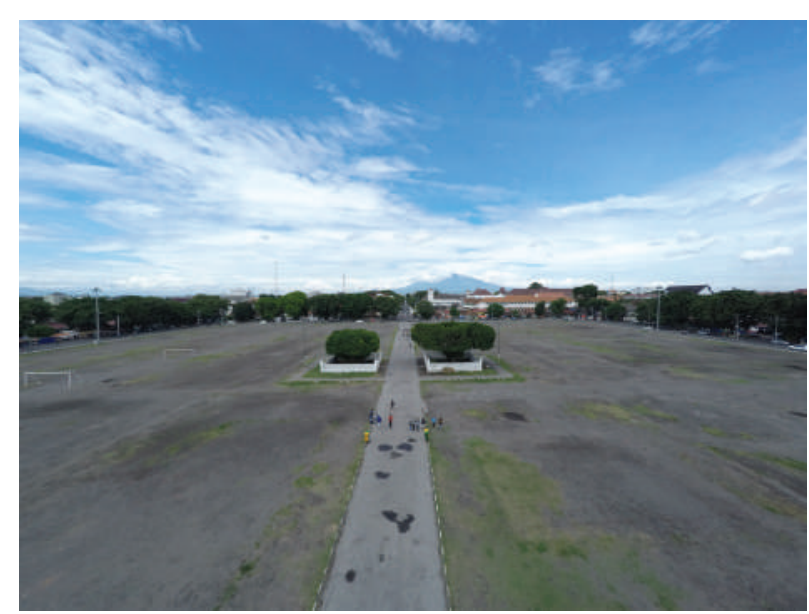

Gambar 6. Alun-Alun Utara

Difoto dengan sudut menyamping/serong (angled/ oblique) dari sisi arah selatan menghadap ke utara. Menampakkan perspektif dan pemandangan ke arah utara yaitu ke arah Gunung Merapi yang berada di sisi paling utara dari poros imajiner.

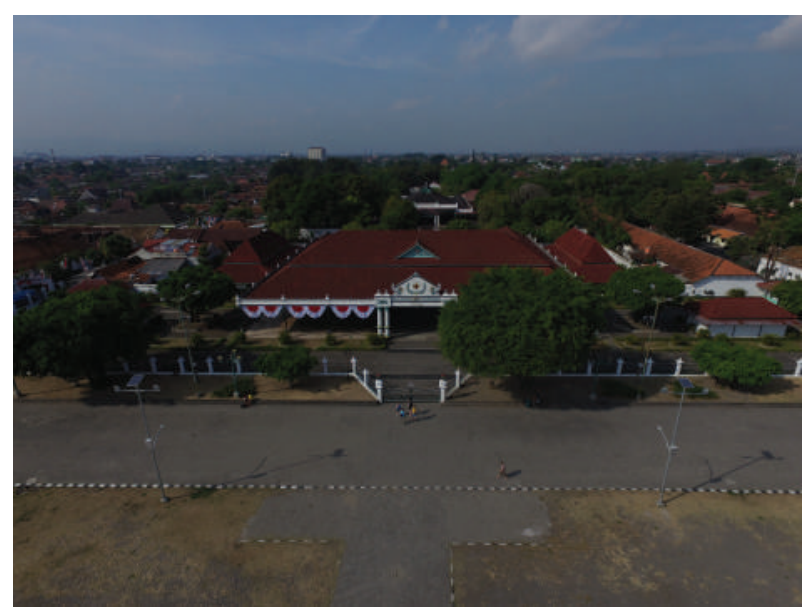

Gambar 7. Keraton Yogyakarta

Difoto dengan sudut menyamping/serong (angled/ oblique) dari sisi utara menghadap selatan. Keraton merupakan titik tengah dari rangkaian poros imajiner. Pemotretan dengan sudut menyamping dan menghadap selatan mengarahkan pandangan dari Keraton ke rangkaian poros imajiner sisi selatan kota Yogyakarta.

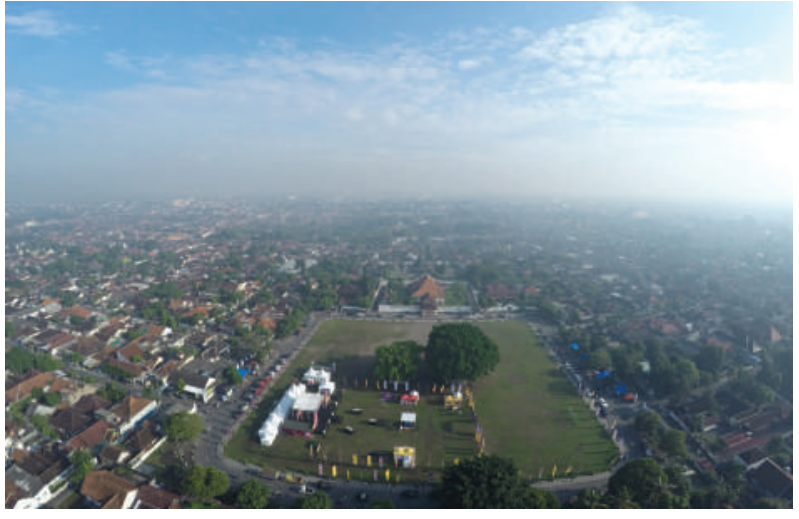

Gambar 8. Alun-Alun Selatan

Difoto dengan sudut menyamping/serong (angled/ oblique) dari sisi selatan menghadap utara. Salah satu keunggulan menggunakan drone adalah dapat melakukan pemotretan dengan posisi dari udara. Dengan demikian perspektif, kesan luas dan keseluruhan pemandangan dapat ditampilkan. Posisi ini berusaha menampilkan rangkaian poros imajiner dari Alun-alun Selatan ke arah utara.

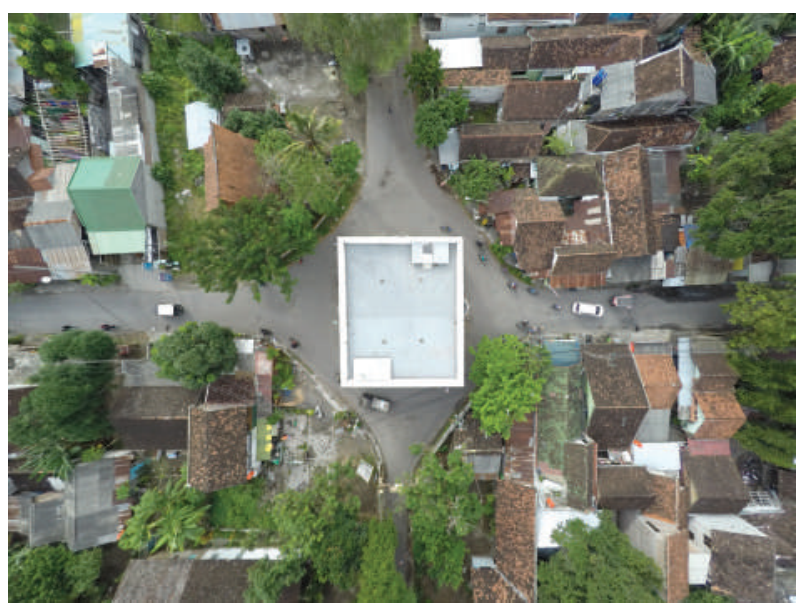

Gambar 9. Kandang Menjangan

Difoto dengan sudut tegak lurus (straight down/ vertical). Sudah banyak foto tentang Kandang Menjangan yang difoto dari bawah, tetapi jarang orang yang melakukan pemotretan dari atas. Dengan demikian muncul pemandangan baru tentang Kandang Menjangan yang difoto dari atas dan menggunakan drone. Karena dengan drone dapat mengeksplorasi berbagai sudut yang mungkin sulit dijangkau ketika menggunakan medium fotografi lainnya. 


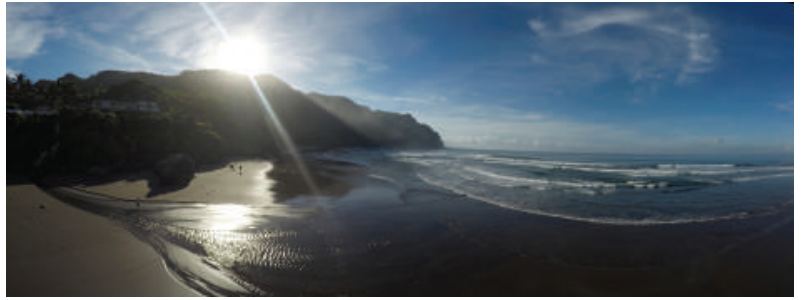

Gambar 10. Pantai Parangtritis

Pantai Parangtritis merupakan titik paling selatan dari poros imajiner, difoto dengan sudut menyamping/serong (angled/oblique). Foto panorama ini merupakan gabungan dari beberapa foto. Untuk menampilkan perspektif dan kesan luas dari sebuah pemandangan salah satunya dapat dicapai dengan cara menggabungkan beberapa foto menjadi sebuah kesatuan pemandangan.

Salah satu keuntungan dari menggunakan cara ini adalah untuk mengurangi efek distorsi kamera jika melakukan pemotretan pemandangan hanya dengan sekali pemotretan (contoh Gambar 8) serta dapat menampilkan detail dengan lebih baik. Pemotretan ini dilakukan dengan menggunakan

drone dan memotret lima bagian dari pantai

Parangtritis, kemudian digabungkan menjadi sebuah foto menggunakan software di komputer.

\section{SIMPULAN}

Penggunaan drone untuk keperluan fotografi udara memberikan kebebasan yang luar biasa dalam penempatan kamera. Hal ini berarti ruang yang hampir tidak terbatas untuk mengeksplorasi berbagai sudut yang mungkin sulit dijangkau ketika menggunakan medium fotografi lainnya. Hal tersebut yang menjadikan karya dengan drone photography tampil berbeda karena menampilkan sesuatu dari sudut yang tidak biasa. Seorang pilot drone dan seorang fotografer adalah dua hal yang berbeda, jika seorang fotografer cenderung mencari yang menarik, sebaliknya seorang pilot cenderung mencari suatu yang aman, sering waktu sesuatu yang menarik itu biasanya tidak aman, dan sebaliknya, kreativitas menjadi jembatan antara dua hal tersebut, tidak hanya menjadi seorang pilot yang bertanggung jawab namun juga seniman yang bertanggung jawab.
Drone hanyalah sebuah alat, hal yang terpenting dan menjadi pembeda dalam sebuah karya adalah ide. Dengan demikian, hal utama yang harus dikembangkan adalah ideasional dan tentunya disusul oleh teknikal, yaitu kemampuan praksis dalam mewujudkan ide tersebut. Jangan takut untuk mencoba hal baru karena dari hal baru tersebut membuka peluang akan muncul ide-ide segar dalam penciptaan sebuah karya. Eksplorasi dan eksperimen dalam pemanfaatan drone untuk fotografi dalam penelitian ini sudah dilakukan semaksimal mungkin, namun demikian apa yang sudah dihasilkan masih dapat dikembangkan lagi karena masih terdapat banyak sekali potensi untuk menghadirkan sebuah karya yang berbeda dengan memanfaatkan drone.

\section{KEPUSTAKAAN}

Cheng, E. (2016). Aerial Photography and Videography Using Drones. San Fransicso: Peachpit Press.

Davis, H. (2010). Creative Composition. Indianapolis: Wiley Publishing.

Hawkess, J. \&, \& McConnel, A. (2003). Aerial: The Art of Photography from the Sky. Mies: Roto Vision.

Papilaya, A. (2015). Drone Foto dan Video. Jakarta: Gramedia Widyasarana Indonesia.

Scrauble, O., \& Sollenberger, R. (2016). Using Drones for Aerial Photography. Berkeley: 3DR.

Setiawan, A. D. (1999). Yogyakarta dari Udara Sebagai Sumber Inspirasi Penciptaan Karya Seni Fotografi. Institut Seni Indonesia Yogyakart.

Soedjono, S. (2007). Pot-Pourri Fotografi. Jakarta: Universitas Trisakti.

Suroso, I. (2018). “Analisis Peran Unmanned Aerial Vehicle Jenis Multicopter dalam Meningkatkan Kualitas Dunia Fotografi Udara di Lokasi Jalur Selatan Menuju Calon Bandara Baru di Kulonprogo." REKAM: Jurnal Fotografi Dan Televisi, 14(1), 17-26. 
Svarajati, T. P. (2013). Photagogos: TerangGelap Fotografi Indonesia. Semarang: Suka Buku.

Yusuf, A. D. (2015). Landmark Yogyakarta Sebagai Objek Penciptaan Karya Fotografi. Universitas Negeri Yogyakarta. 